\title{
Sexual dimorphism in atrophic effects of topical glucocorticoids is driven by differential regulation of atrophogene REDD1 in male and female skin
}

\author{
Gleb Baida ${ }^{1}$, Shivani Agarwal' ${ }^{1}$, Ben Readhead ${ }^{2,3}$, Joel T. Dudley ${ }^{2}$ and Irina Budunova ${ }^{1}$ \\ ${ }^{1}$ Feinberg School of Medicine, Department of Dermatology, Northwestern University, Chicago, IL, USA \\ ${ }^{2}$ Icahn School of Medicine at Mount Sinai, New York, NY, USA \\ ${ }^{3}$ Current address: ASU-Banner Neurodegenerative Disease Research Center, Arizona State University, Tempe, AZ, USA \\ Correspondence to: Irina Budunova, email: i-budunova@northwestern.edu \\ Keywords: glucocorticoid; skin atrophy; REDD 1; mTOR; sexual dimorphism \\ Received: December 05, $2019 \quad$ Accepted: January 04, $2020 \quad$ Published: January 28, 2020
}

Copyright: Baida et al. This is an open-access article distributed under the terms of the Creative Commons Attribution License 3.0 (CC BY $3.0)$, which permits unrestricted use, distribution, and reproduction in any medium, provided the original author and source are credited.

\section{ABSTRACT}

Topical glucocorticoids, well-known anti-inflammatory drugs, induce multiple adverse effects, including skin atrophy. The sex-specific effects of systemic glucocorticoids are known, but sexual dimorphism of therapeutic and side effects of topical steroids has not been studied. We report here that female and male mice were equally sensitive to the anti-inflammatory effect of glucocorticoid fluocinolone acetonide (FA) in ear edema test. At the same time, females were more sensitive to FAinduced skin atrophy. We recently reported that REDD1 (regulated in development and DNA damage 1) plays central role in steroid atrophy. We found that REDD1 was more efficiently activated by FA in females, and that REDD1 knockout significantly protected female but not male mice from skin atrophy. Studies using human keratinocytes revealed that both estradiol and FA induced REDD1 mRNA/protein expression, and cooperated when they were combined at low doses. Chromatin immunoprecipitation analysis confirmed that REDD1 is an estrogen receptor (ER) target gene with multiple estrogen response elements in its promoter. Moreover, experiments with GR and ER inhibitors suggested that REDD1 induction by these hormones was interdependent on functional activity of both receptors. Overall, our results are important for the development of safer GR-targeted therapies suited for female and male dermatological patients.

\section{INTRODUCTION}

Glucocorticoids (GCs) are important regulators of skin cell proliferation, differentiation, and immune response. They are synthesized in adrenal glands but also in peripheral tissues including skin [1-3], and their biosynthesis is tightly regulated $[4,5]$. Synthetic GCs are among the most effective and frequently used antiinflammatory drugs for different inflammatory and autoimmune skin diseases, including atopic dermatitis and psoriasis. Unfortunately, chronic treatment with GCs results in multiple deleterious side effects, including skin atrophy.

Skin atrophy involves all skin compartments and is characterized by a dramatic loss in skin thickness, increased fragility, tearing, bruising, and results in compromised skin barrier function, followed by the increased risk for developing secondary wounds and infections at the affected site [6-10]. Although GCsinduced skin atrophy is well described at the phenotypic level, the underlying molecular mechanisms just started to emerge. Recently we and others identified mTOR/Akt inhibitor REDD1 (regulated in development and DNA damage 1) as the key mediator of GCs-induced atrophy in skin and muscle. Indeed, in REDD1 KO animals muscle as well as all skin compartments: epidermis, dermis, and dermal adipose were protected against GCs-induced atrophy $[11,12]$.

It is well known that sex steroid hormones profoundly affect various aspects of normal skin morphology, physiology, as well as risk for certain cutaneous diseases. For example, sex steroids affect skin thickness, skin surface $\mathrm{pH}$, wound healing [13,14]. Women exhibit a higher prevalence of inflammatory and autoimmune skin and other diseases such as rosacea, lupus, and scleroderma 
[15-17]. Interestingly, in murine skin, estrogens play an important role in the control of epidermis and dermal adipose, while dermis is controlled by androgens [13]. In humans, it is well documented that thinning of the skin and loss of dermal collagen occur with the loss of circulating estrogens in postmenopausal women $[18,19]$.

The sex-specific effects of systemically administered GCs on immune and central nervous systems, and liver are known, and this dimorphism is linked to the differential gene expression regulation by GCs in males and females $[16,17,20]$. These previous findings indicated that males are overall more sensitive to the anti-inflammatory effect of systemic GCs than females. However, the sex dependence of therapeutic and side effects of topical steroids has not been documented or explored, even though it is pertinent to the treatment regimens optimization in patients. Indeed, currently, topical (as well as systemic) glucocorticoids are prescribed at similar doses and regiments to men and women. In fact, until recent years, only few dermatological research papers compared the effects of different compounds including hormones in male versus female cells or animals, and the vast majority of authors either do not disclose sex or use only one sex in their work [15].

The goal of studies presented here was to compare the response of male and female mice to anti-inflammatory and atrophogenic effects of topical GCs, and to further corroborate the role of atrophogene REDD1 in skin with a focus on sexually dimorphic response to these steroid hormones.

We found that male and female mice were equally sensitive to the anti-inflammatory effect of topical glucocorticoid fluocinolone acetonide (FA) in the ear edema test. Unexpectedly females appeared more sensitive to FA-induced skin atrophy, especially when lower doses of glucocorticoid fluocinolone acetonide (FA) were used. This was in part due to more efficient REDD1 induction in female skin. Moreover, knockout (KO) of REDD1 protected females but not males against atrophic side effects of topical GCs. REDD1 is a known glucocorticoid receptor (GR) target gene [21-23, 12]. Here we report that estrogen receptor (ER) also controls REDD1 expression, and that GCs and estrogens cooperated in the induction of REDD1 in keratinocytes.

\section{RESULTS}

\section{Male and female mice are equally sensitive to the anti-inflammatory effects of glucocorticoids}

In order to quantitatively assess the antiinflammatory effects of glucocorticoids, we employed a widely used ear edema test [24]. The inflammation was induced by topical application of skin irritant croton oil $(5 \%$ in $20 \mu \mathrm{l}$ acetone) to the ears of F1 B6 $\times 129$ wild-type mice, and ear edema (measured $9 \mathrm{~h}$ later by ear punch weight) was used as the readout for general inflammatory response. The glucocorticoid FA was applied $1 \mathrm{~h}$ before the croton oil. As shown in Figure 1, male and female mice showed equal edema after croton oil and were equally sensitive to FA-induced inhibition of ear inflammation over a broad range of doses with complete inhibition of swelling at $1 \mu \mathrm{g}$ FA for both sexes. Thus, we found no sexual dimorphism in the induction of inflammation or in the anti-inflammatory effects of glucocorticoid FA in the skin.

\section{Females are more sensitive to skin atrophy induced by topical glucocorticoids due to the more effective induction of atrophogene REDD1}

An undesirable side effect of chronic topical glucocorticoid treatment is skin atrophy. To assess whether there is a sexually dimorphic response to steroid-induced atrophy, we used the previously developed skin atrophy model $[12,25]$. Skin hypoplasia was induced by the range of FA doses $(0.2-2 \mu \mathrm{g} /$ animal $)$ applied dorsally twice a week for 2 weeks. As epidermis is considered the most sensitive skin compartment in terms of atrophic response, and the measurements of epidermal thickness were included in the test system for steroid skin atrophy $[8,26]$, we used morphometric analysis of epidermal thickness as the readout for development of skin atrophy. Our experiments revealed that epidermis in female mice was more sensitive to FA atrophogenic effect at low doses (0.2-0.5 $\mu \mathrm{g}$, Figure 2A). However, at higher $(2 \mu \mathrm{g})$ dose FA was equally effective in the induction of skin atrophy in mice of both sexes (Figure 2A). It is known that dermal adipose is also very sensitive to topical glucocorticoids, and could undergo severe atrophy until almost complete reduction during chronic topical treatment $[9,12]$. Interestingly, the analysis of FA effect on dermal adipose at low doses, including $0.04 \mu \mathrm{g}$, the dose that practically did not affect epidermis, confirmed higher sensitivity of females to atrophic effects of glucocorticoids (Supplementary Figure 1). The quantitative analysis of dermal adipose at higher doses was not possible due to the loss of most part of this fat depot.

We have recently identified several atrophogenes, genes that are required for the induction of skin atrophy by glucocorticoids, including mTOR/Akt inhibitor REDD1 $[12,27]$. We reported earlier that REDD1 is strongly induced in mouse and human skin by glucocorticoids and its knockout renders mice resistant to glucocorticoidinduced skin atrophy [12]. We show here that REDD1 was induced by FA earlier and more efficiently at low doses in the female epidermis (Figure 2B, 2C), which correlated well with higher sensitivity of females to steroid skin atrophy.

Our previous observation that knockout of REDD1 provided a protective effect from FA-induced skin atrophy was done in female mice [12]. We repeated these experiments in female and male REDD1 KO and isogenic 
wild-type animals. As REDD1 KO animals have mild epidermal hyperplasia and more extensive dermal adipose [12], we evaluated skin hypoplasia via comparison of FAtreated animals with corresponding (sex/genotype) vehicle control groups (Figure 3A). Chronic FA treatment (2 $\mu \mathrm{g}$ twice a week for 2 weeks) resulted in $\sim 40 \%$ thinning of the epidermis in wild-type males and $\sim 50 \%$ in $\mathrm{KO}$ males (Figure 3B). At the same time, the epidermal thickness was reduced by more than $50 \%$ in wild-type females, but only by $20 \%$ in REDD1 KO females. The similar sexdepended effect was observed in dermal adipose, which was protected from FA-induced atrophy only in female REDD1 KO animals (Supplementary Figure 2). Thus, knockout of REDD1, protective in female skin, did not significantly spare skin from glucocorticoid-induced atrophy in males.

\section{REDD1 is the ER target gene, and its expression is co-regulated by glucocorticoids and estrogens}

The results of our in vivo experiments suggested that the potential cross-talk between estrogen- and glucocorticoid-induced signaling may play an important role in the regulation of REDD1 expression in skin. To examine the potential effects of steroid hormones on REDD1 expression, we used human immortalized keratinocyte cell line HaCaT. In these cells, GR is well expressed and highly functional $[12,23]$. They also express estrogen receptors, ER $\alpha$ and ER $\beta$, which mediate estrogen signaling, as well as androgen receptor, $\operatorname{AR}[28,29]$.

REDD1 is a well-known GR target gene with multiple GR-binding sites in its promoter [21-23, 30]. As expected, glucocorticoid FA robustly induced REDD1 expression in 6-24 h (Figure 4A). Interestingly, estrogen $\left(\mathrm{E}_{2}\right)$ was also able to significantly induce REDD1 expression, while AR ligand dihydrotestosterone (DHT) had little effect on REDD1 levels (Figure 4A). In order to determine if glucocorticoids and estrogens may act cooperatively, $\mathrm{HaCaT}$ cells were treated with fairly low $\left(10^{-9} \mathrm{M}\right)$ doses of FA and $\mathrm{E}_{2}$ that were minimally effective for REDD1 induction when used alone. However, the combination of FA and $\mathrm{E}_{2}$ resulted in a much greater induction of REDD1 at both mRNA (Figure 4B) and protein (Figure 4C) levels compared to the single hormone treatment.

To further assess the role of GR/ER crosstalk in cooperative REDD1 regulation by steroids, we blocked

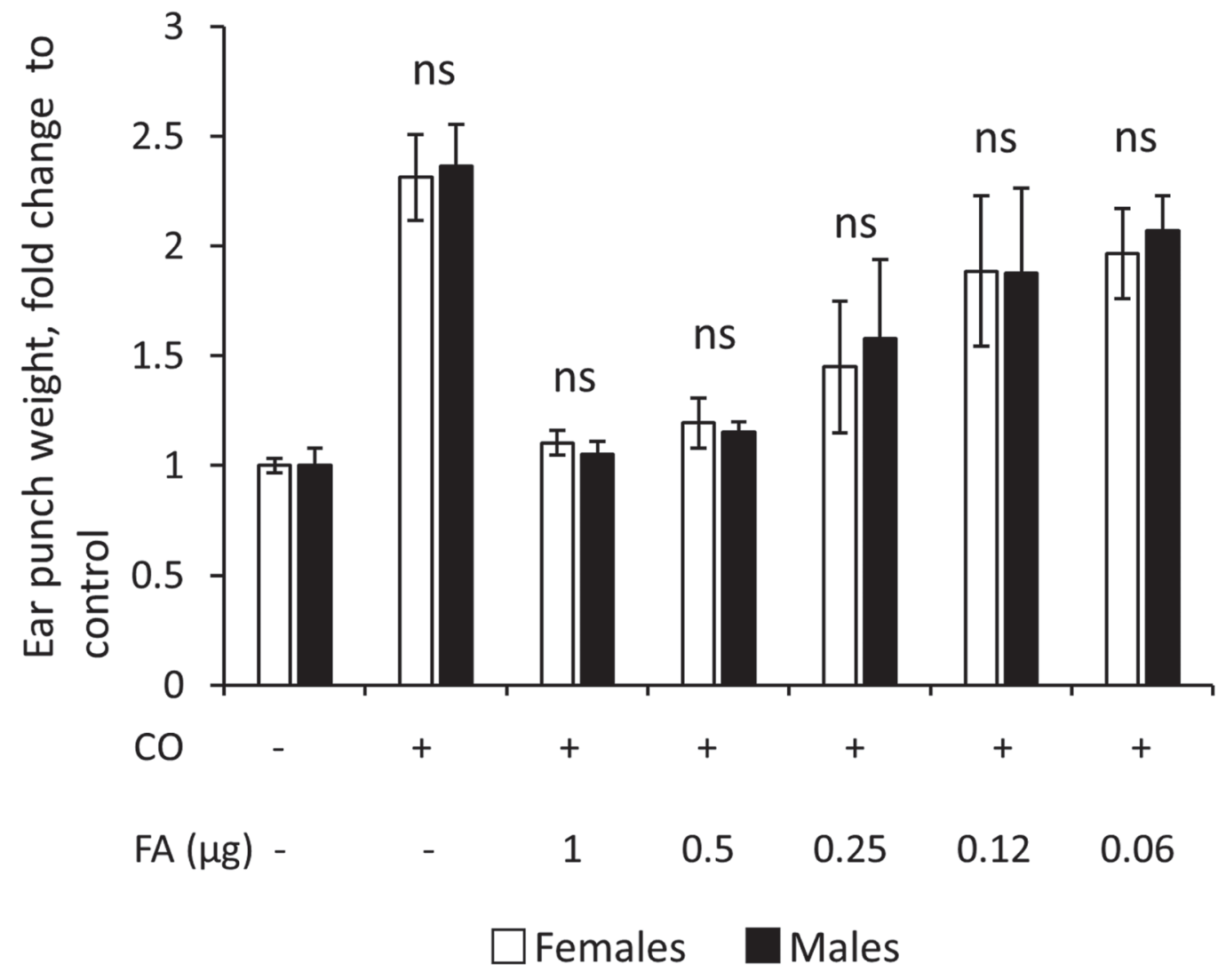

Figure 1: Similar sensitivity of males and females to inflammation and anti-inflammatory effects of glucocorticoid FA in ear edema test. Ear edema was induced by croton oil (CO) in 7-week-old female and male wild-type F1 B6 $\times 129$ mice as in Materials and Methods. FA was applied $1 \mathrm{~h}$ before CO, and five-millimeter ear punches were weighed $9 \mathrm{~h}$ after $\mathrm{CO}$ application to assess swelling. Results are presented as fold changes to corresponding (female or male) control ear weight. The means \pm SD were calculated for six individual ear punches/condition in one representative experiment. The unpaired two-tailed $t$-test was used for statistical analysis for differences between males and females in the same treatment groups. In all cases the differences were non-significant (ns, $P>0.3$ ). 
GR and ER functions using their antagonists RU0486 (for GR) and Fulvestrant (for ER). Reflecting the known role of GR in REDD1 gene expression regulation, RU0486 alone significantly blocked basal REDD1 expression (Figure 4D), while Fulvestrant had only borderline effect on REDD1 basal level. Interestingly, the pre-treatment of cells with RU0486 blocked not only GR-dependent REDD1 induction but $\mathrm{E}_{2}$-induced REDD1 induction as well (Figure 4D). Similarly, ER antagonist, Fulvestrant, blunted both $\mathrm{E}_{2}-$ and FA-induced REDD1 induction (Figure 4D), suggesting that REDD1 induction in response to these steroid hormones is interdependent on functional activity of both these receptors.

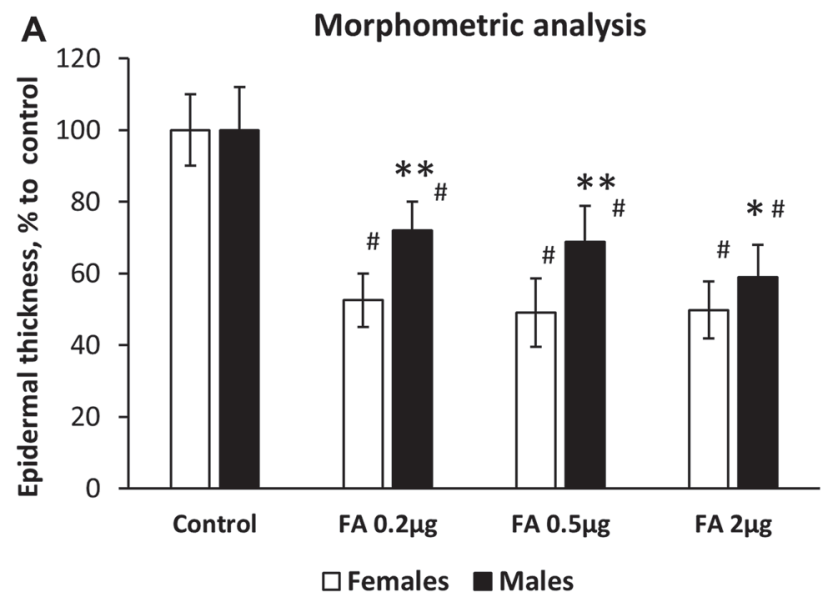

C
To further understand the mechanism of REDD1 induction by $E_{2}$, we assessed whether ER loads on estrogen response elements (EREs) in the promoter region of the human REDD1 gene. Putative ER binding sites in the human REDD1 promoter were predicted based on HOCOMOCO models of TF binding motifs [31] as described in Materials and Methods. We used ChIP analysis of seven putative ER binding sites and found that ER indeed occupied all these predicted sites in cells treated with $\mathrm{E}_{2}$, thereby explaining the possible mechanism of REDD1 induction by estrogens (Figure 4E).
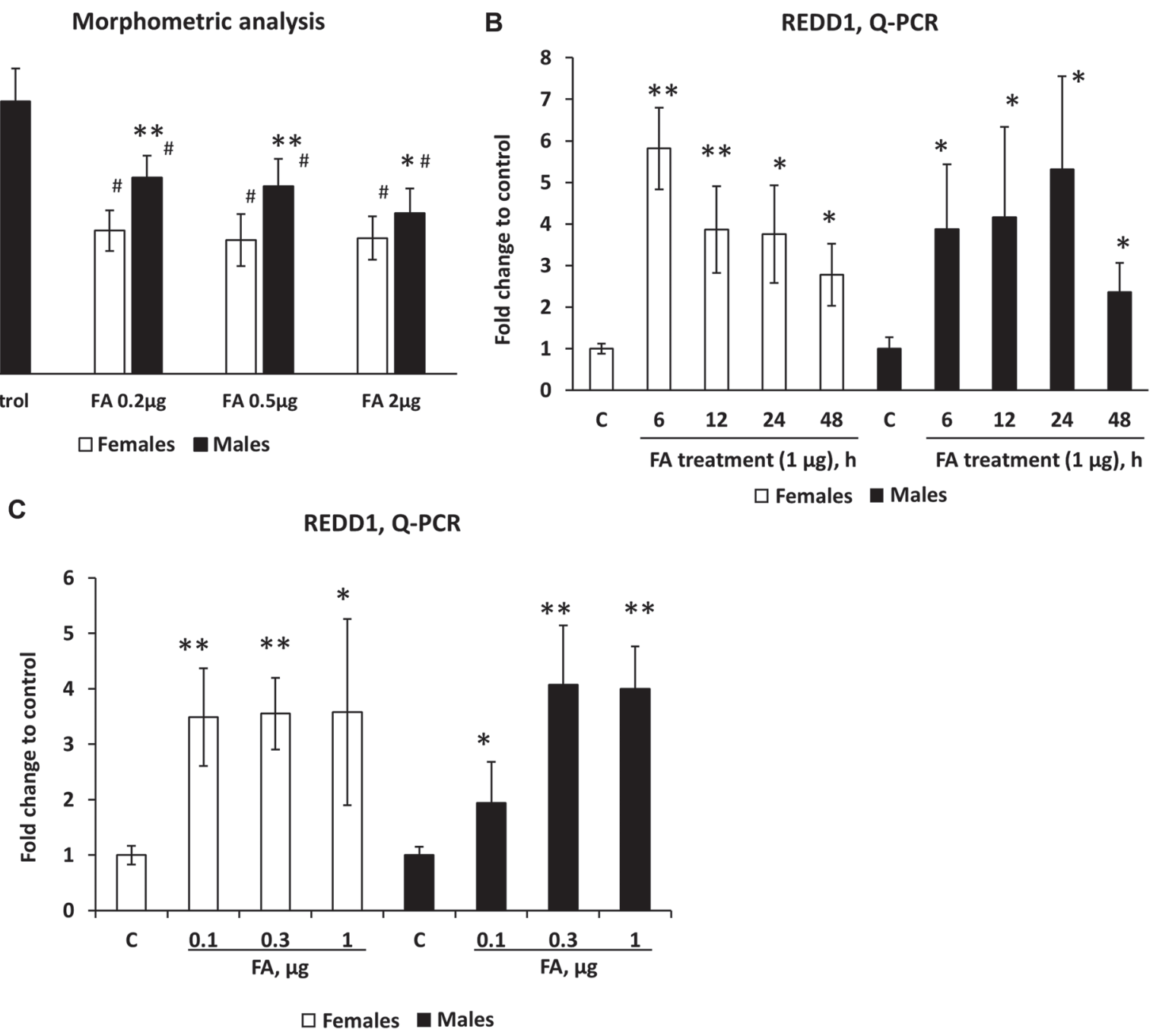

Figure 2: Females are more sensitive than males to REDD1 induction and glucocorticoid FA-induced skin atrophy. Seven-week-old female and male wild-type F1 B6 × 129 mice were treated topically with vehicle (Control, $200 \mu 1$ acetone) or FA (at indicated doses) every $72 \mathrm{~h}$ for 2 weeks (A) or once for 6-48 h (B) or once for $24 \mathrm{~h} \mathrm{(C).} \mathrm{(A)} \mathrm{Epidermal} \mathrm{atrophy} \mathrm{induced} \mathrm{by} \mathrm{chronic} \mathrm{FA}$ applications was assessed by morphometric analysis of epidermal thickness in H\&E skin sections as in Materials and Methods. Changes in epidermal width are presented as \% to corresponding control epidermis. The means \pm SD were calculated for three individual skin samples per condition in one representative experiment (totally 30 measurements/condition). The unpaired two-tailed $t$-test was used for statistical analysis: ${ }^{*} P<0.01,{ }^{* *} P<0.0001$, for differences between atrophy in males compared to females in the same treatment group; ${ }^{\sharp} P<0.0001$, for changes compared to corresponding controls. (B and C) REDD1 mRNA expression in mouse epidermis was measured by Q-PCR as in Materials and Methods. Rp127 was used as a cDNA normalization control. Q-PCR results are the means \pm SD calculated for three individual RNA samples/condition. Statistical analysis for differences between treatment and corresponding control was done by the unpaired twotailed $t$-test. ${ }^{*} P<0.05 ;{ }^{* *} P<0.01$. 
A
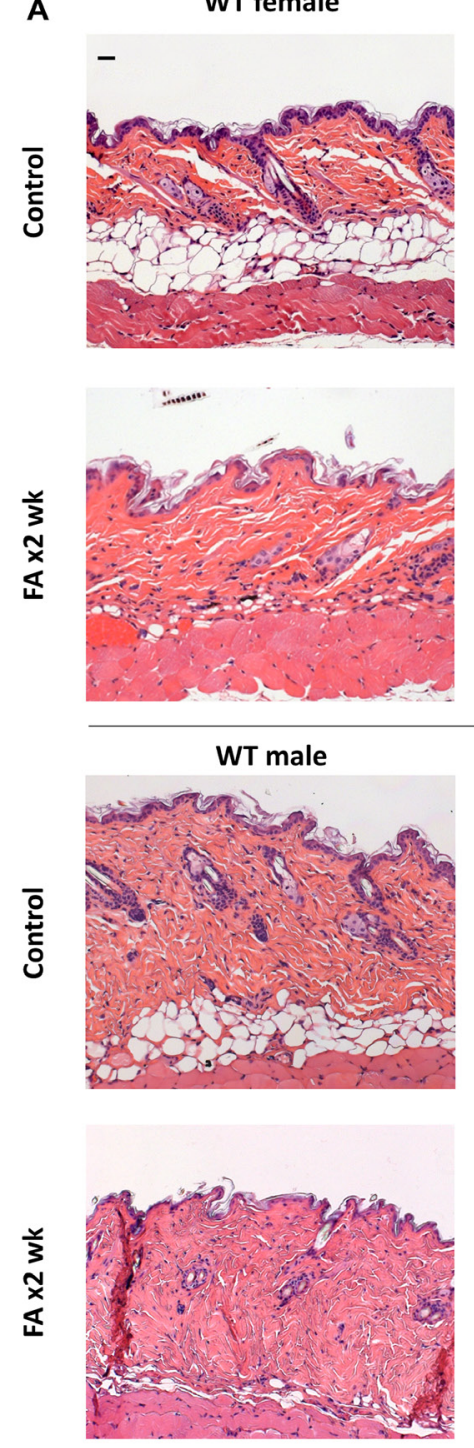

REDD1 KO female
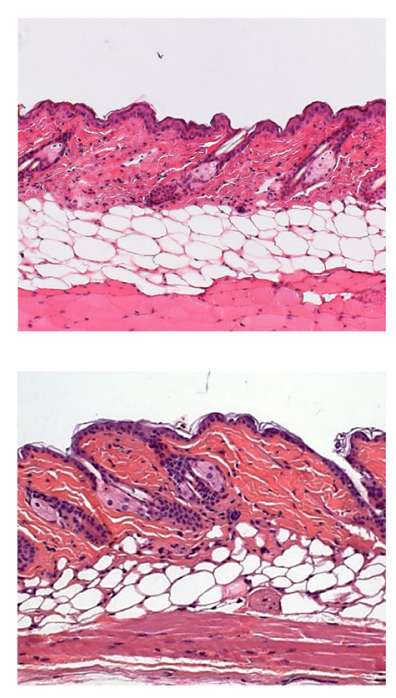

REDD1 KO male
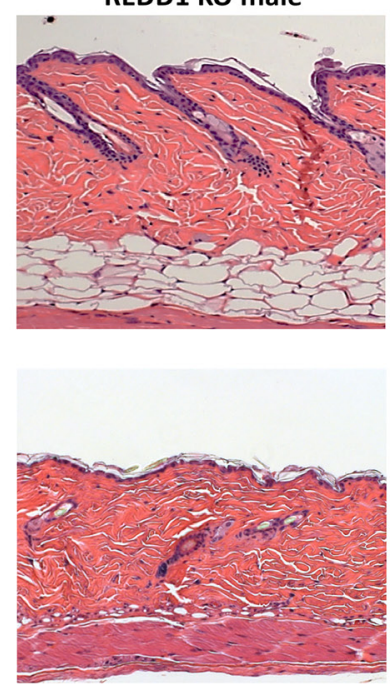

Males
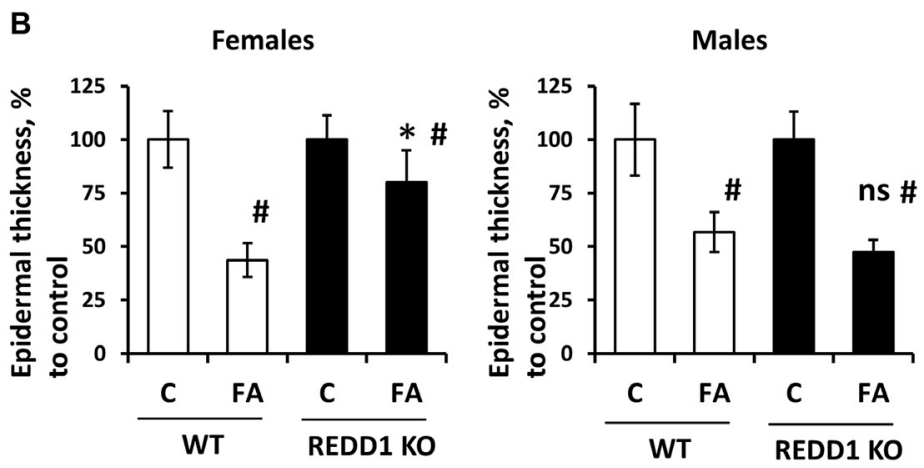

Figure 3: REDD1 KO female but not male mice are protected against glucocorticoid FA-induced skin atrophy. Sevenweek-old F1 B6 $\times 129$ WT and REDD1 KO male and female mice were treated with vehicle (Control, $200 \mu 1$ acetone) or FA (2 $\mu \mathrm{g} / \mathrm{animal})$ every $72 \mathrm{~h}$ for 2 weeks. (A) Formalin-fixed, paraffin-embedded skin sections stained with hematoxylin and eosin. Scale bars are $20 \mu \mathrm{m}$. (B) Epidermal thickness in female and male WT and REDD1 KO mice was evaluated as in Materials and Methods. Epidermal thickness is presented as \% to corresponding (sex/genotype) control epidermis. The means $\pm \mathrm{SD}$ were calculated for three individual skin samples in one representative experiment (totally 30 measurements/condition). The unpaired two-tailed $t$-test was used for statistical analysis: " $P<$ 0.001, for differences between atrophy in WT and REDD1 KO females; ns, $(P>0.3)$ for differences between atrophy in WT and REDD1 KO males; ${ }^{*} P<0.001$, for changes compared to corresponding controls. Note: Only in REDD1 KO female epidermis and dermal adipose were significantly protected against FA-induced hypoplasia. 


\section{DISCUSSION}

The major goal of this work was to evaluate whether and how the responses to anti-inflammatory and adverse effects of topical GCs depend on sex in animal models of dermatitis and skin atrophy. We found that the anti-inflammatory effect of glucocorticoid FA was similar in male and female mice in the ear edema test. This result is different from the previously reported larger inflammation-related Dexamethasone molecular signature in the liver of male rats, and higher susceptibility of male rats to anti-inflammatory actions of systemic
Dexamethasone in a sepsis model [16]. This discrepancy probably reflects the significant difference in models and routs of GCs delivery. In addition, our recent analysis of sexual dimorphism in the molecular signature of topical glucocorticoid clobetasol propionate in human skin [32] did not reveal either the increased gene down-regulation or the increased number of inflammation-related DEGs in human male skin, suggesting that sexually dimorphic effects of GCs are tissue-specific.

Further, the analysis of skin atrophy induced by chronic topical FA showed higher sensitivity of female mice to atrophic effects of lower FA doses. This was
A
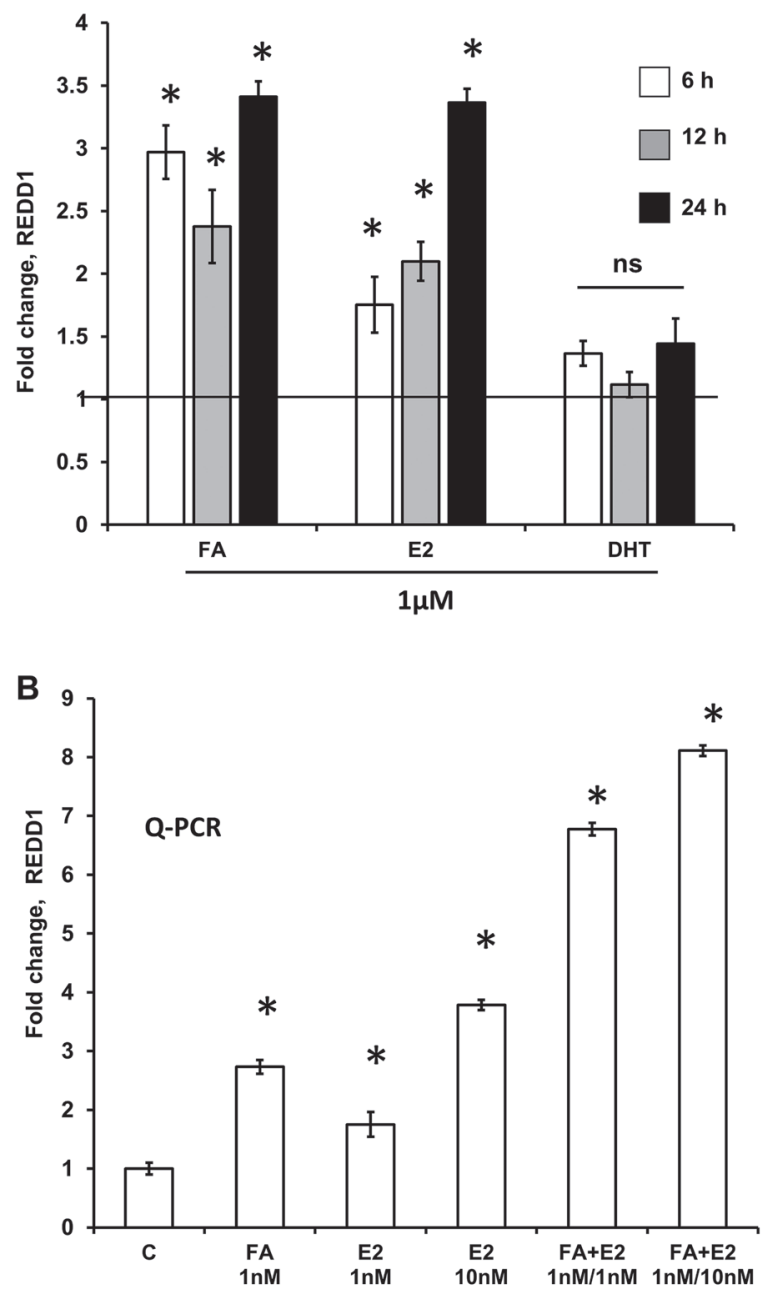

C

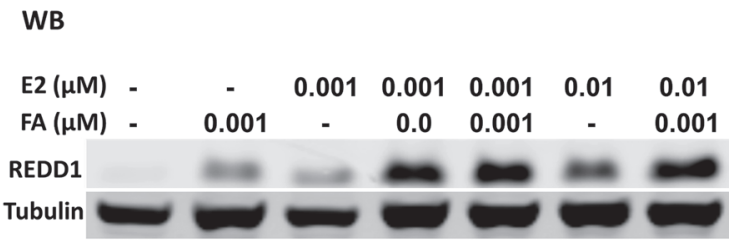

D

WB

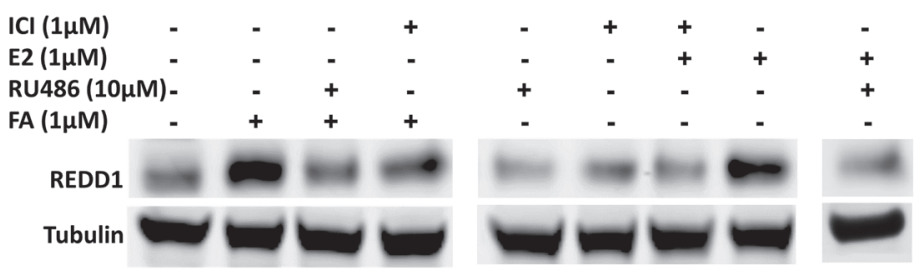

E

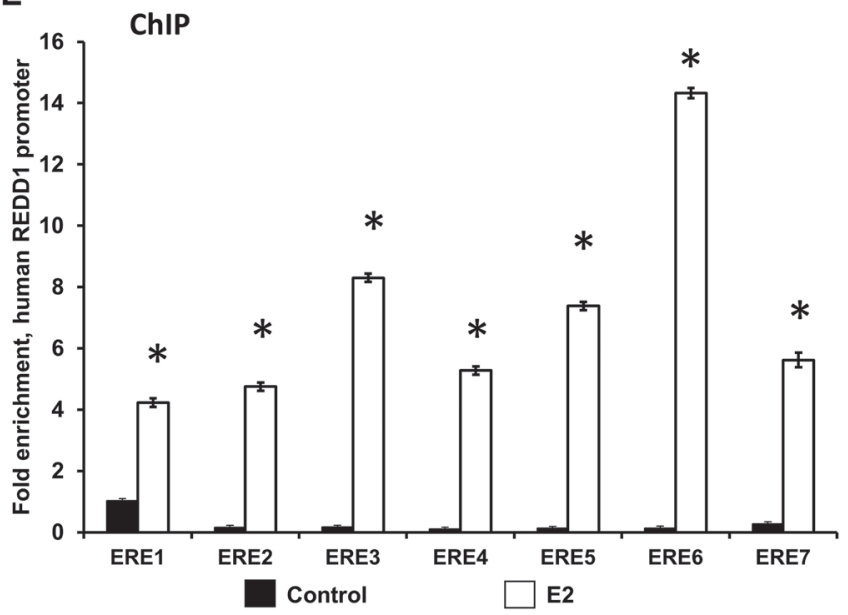

Figure 4: REDD1 expression in keratinocytes is co-regulated by glucocorticoids and estrogens. Immortalized human keratinocytes $\mathrm{HaCaT}$ were switched to hormone-free medium for $24 \mathrm{~h}$ as in Materials and Methods and treated with steroid hormones and inhibitors as detailed below. (A) Q-PCR analysis of REDD1 induction by glucocorticoid FA, estradiol ( $\left.\mathrm{E}_{2}\right)$, and androgen DHT (1 $\mu \mathrm{M}$ for 6-24 h). (B and C) $\mathrm{E}_{2}$ and FA cooperatively induced REDD1 expression at low concentrations (1 $\mathrm{nM}-10 \mathrm{nM}$ for $12 \mathrm{~h}$ ), as detected by Q-PCR (B) and Western blotting (C). ${ }^{*} P<0.01$, for changes compared to control, two-tailed unpaired $t$-test (A and B). (D) Western blot analysis of REDD1 expression in HaCaT cells pre-incubated for $6 \mathrm{~h}$ with GR inhibitor RU486 or ER inhibitor ICI182,780 (Fulvestrant), and then treated with either FA or $\mathrm{E}_{2}$ for $24 \mathrm{~h}$. Control cells were treated with solvent only ( $0.1 \%$ Etoh). Tubulin was used as a loading control. (E) ChIP analysis of ER loading on REDD1 promoter. HaCaT cells grown in steroid-free medium as in Materials and Methods, were treated with a vehicle (control, $0.01 \mathrm{EtOH})$ or estradiol $\left(\mathrm{E}_{2}, 1 \mu\right)$ for $24 \mathrm{~h}$ and processed for ChIP (3 independent experiments) as in Materials and Methods. ${ }^{*} P<0.001$, for changes compared to control, two-tailed unpaired $t$-test. 
rather unexpected in view of protective anti-atrophic effects of estrogen in naturally aging skin mostly studied in postmenopausal women [19, 33].

In our previous studies we discovered that REDD1, a stress-inducible inhibitor of mTOR/Akt, acts as atrophogene in the skin [12], and we were able to prevent steroid-induced skin hypoplasia in female mice by using pharmacological REDD1 inhibitors [23, $30]$. We report here that there was a sexually dimorphic response to glucocorticoid FA in terms of REDD1 induction: in female skin, REDD1 expression was induced earlier and more efficiently, which correlated well with higher sensitivity of females to FA-induced atrophy. Interestingly, we also found that REDD1 knockout protected preferentially females but not males from skin hypoplasia. Together these results suggest that estrogen-enhanced glucocorticoid induction of REDD1 acts as a central driver of skin atrophy in females, but not in males, and that enhanced induction of REDD1 contributes to the greater sensitivity of females to steroid skin atrophy.

The effects of glucocorticoids and estrogens are mediated by their cognate receptors, GR and ER, which are well-known ligand-activated transcription factors from the family of steroid hormone receptors (SHR) [34]. Even though SHR-regulated transcription was initially studied as single receptor events, mediated by SHR homodimers [35], it is becoming evident that SHR crosstalk with each other and frequently co-regulate gene expression [34]. ER/GR crosstalk was extensively studied in hormone-dependent tissues such as uterus and breast, and in hormone-dependent cancers [34, 36-38]. Even though there has been a perception in the literature that GR and ER effects on gene expression are frequently reciprocal, careful literature analysis revealed that GR/ ER interactions are much more complex and cell and gene context-dependent. Indeed, there is an extensive overlap in ER and GR chromatin binding; both hormones induce global reprogramming of chromatin landscape that affects DNA accessibly for both receptors [36, 38]. Moreover, upon co-activation, increased GR chromatin binding was observed at ER response elements, and at the same time, ER was associated with GR response elements, suggesting that ER and GR interact in a complex $[34,36,38]$. Further, analysis of the global effects of estrogens and GCs on transcriptome revealed similar effects of both hormones on individual gene expression $[36,39,40]$. There is also experimental evidence suggesting direct physical ER-GR interaction on protein-protein level [37], which further supports the results of global transcriptome analysis.

REDD1 is a known target gene for GR with multiple GRE in its promoter [21-23]. We report here that REDD1 is also a target gene for ER, and that its expression is cooperatively regulated by estrogens and glucocorticoids used in low, sub-threshold doses. Moreover, in correlation with the findings in other cell types, we observed that the steroid hormone effect on REDD1 expression depended on the functional activity of both ER and GR as the use of either of their antagonists blocked FA- and $\mathrm{E}_{2}$-dependent REDD1 induction.

In conclusion, we have demonstrated that there is sexual dimorphism in the adverse side effects of topical glucocorticoids but not in their anti-inflammatory effects. We found that female mice were more prone to glucocorticoid-induced skin atrophy than males due to the cooperative induction of REDD1 by estrogens and glucocorticoids. These observations are clinically important and suggest that our efforts focused on the development of safer GR-targeted therapy with topical glucocorticoids combined with anti-atrophogenes, including REDD1 inhibitors [23,30] are more applicable for female patients suffering from inflammatory and hyperproliferative skin diseases and disorders.

\section{MATERIALS AND METHODS}

\section{Chemicals, reagents, and antibodies}

Fluocinolone acetonide (FA), E, DHT, RU0486 (Mifepristone), and ICI182,780 (Fulvestrant) were from Sigma-Aldrich (St. Louis, MO, USA). Croton oil (CO) was from Santa Cruz Biotechnology (Dallas, TX, USA). We used antibodies against GR (Santa Cruz Biotechnology), ER (EMD Millipore, Danvers MA, USA), REDD1 (Proteintech Group, Rosemont, IL, USA), GAPDH (Sigma-Aldrich), tubulin, and normal IgG (Cell Signaling, San Jose, CA, USA).

\section{Animals}

The REDD1 KO breeder mice in F1 C57BL/6 $\times 129 \mathrm{~S}$ genetic background were kindly provided by Quark Pharmaceuticals Inc. (Newark, CA, USA); wildtype (WT) isogenic C57BL/6 $\times 129 \mathrm{~S}$ breeder mice were obtained from Taconic (Germantown, NY, USA). Both colonies were bread at Northwestern University vivarium.

\section{Ear edema test}

For evaluation of the anti-inflammatory effect of glucocorticoid FA, we used the ear edema test $[19,7]$. Seven-week-old WT mice of both sexes were pretreated with FA (0.06-1 $\mu \mathrm{g}$ in $20 \mu \mathrm{l}$ of acetone) or vehicle (20 $\mu \mathrm{l}$ of acetone) administered to the back of the ear lobe $1 \mathrm{~h}$ before application of nonspecific contact irritant croton oil (5\% solution in $20 \mu \mathrm{l}$ of acetone). Mice were euthanized, and ears were harvested $9 \mathrm{~h}$ after the croton oil application; at this time point we observed maximum ear edema in B6 $\times 129$ animals [12]. Five-millimeter ear punch biopsies were weighted to measure ear swelling as a readout for inflammation. 


\section{GCs-induced skin atrophy and acute topical dorsal skin treatments}

Seven-week-old mice in the telogen stage of the hair cycle were shaved on the back and 3 days later treated with FA or vehicle as described below.

\section{Acute treatment}

Animals were treated with FA applied topically $(0.1-2 \mu \mathrm{g} /$ mouse) in $200 \mu \mathrm{l}$ acetone to the back skin, control animals were treated with acetone. The skin was harvested in 6-48 h, and epidermis, mechanically separated from dermis, was used for RNA isolation as described [12].

\section{Chronic treatment to induce skin atrophy}

Skin atrophy was induced by chronic FA treatment (0.1-2 $\mu$ g every $72 \mathrm{~h}$ for 2 weeks), as previously described [12]. Mice were sacrificed, and skin was harvested 24 hours after the last FA treatment.

In all experiments, we used 3-4 mice/group; experiments were repeated 2-3 times. All animal experiments were performed according to protocols approved by Northwestern University Animal Care and Use Committee.

\section{Histological analysis and morphometry}

Skin was fixed with formalin, and paraffinembedded sections were stained with hematoxylin and eosin (H\&E). Quantification of the epidermal and dermal adipose width (as the readout for skin thinning) was performed as described [12,30]. At least 10 fields of view/ slide in each of three individual samples/experimental group (30 images/ group) were analyzed using Axioplan2 microscope software (Carl Zeiss).

\section{Cells and treatments}

Immortalized human keratinocyte cell line $\mathrm{HaCaT}$ was a kind gift of Dr. K. J. Green (Northwestern University, Chicago, IL, USA). The cells were maintained in DMEM medium supplemented with $10 \%$ fetal bovine serum (FBS), $100 \mathrm{U} / \mathrm{mL}$ penicillin, $100 \mu \mathrm{g} / \mathrm{mL}$ streptomycin. Before treatments, cells were switched to hormone-free medium (Phenol red-free DMEM with 10\% charcoal-stripped serum) for $24 \mathrm{~h}$ and then treated with glucocorticoid FA, estradiol $\left(\mathrm{E}_{2}\right)$ or dihydrotestosterone (DHT) for 6, 12 or $24 \mathrm{~h}$, as described in Figure legends. In some experiments, cells were pre-incubated for $6 \mathrm{~h}$ with RU0486 (Mifepristone, $10 \mu \mathrm{M}$ ) and ICI182,780 (Fulvestrant, $1 \mu \mathrm{M}$ ) used as GR and ER inhibitors, respectively. $\mathrm{E}_{2}$ and FA were dissolved in ethanol, DHT in methanol, and inhibitors in DMSO.

\section{Western blot analysis}

Whole-cell protein extracts were prepared as described [12], resolved on 4-15\% gradient SDS-PAGE, and transferred to nitrocellulose membranes (LI-COR Biosciences; Lincoln, NE, USA). Membranes were blocked and incubated with primary antibodies overnight at $4{ }^{\circ} \mathrm{C}$, followed by IRDye ${ }^{\circledR}$ secondary antibodies (LICOR Biosciences). LI-COR Odyssey Imager was used for band visualization. The antibodies were used at concentrations recommended by their manufacturers. GAPDH and tubulin were used as loading controls.

\section{RNA preparation and quantitative PCR}

RNA from epidermis was isolated with the RiboPure kit (Ambion/Life Technologies; Grand Island, NY, USA) and treated with TURBO ${ }^{\text {TM }}$ DNase (Ambion). Reverse transcription was performed on $1 \mu \mathrm{g}$ RNA, using random hexamers and M-MLV reverse transcriptase (Invitrogen/ Life Technologies) as described [23]. The REDD1-specific primers were designed with NCBI Primer-BLAST (REDD1 forward primer: 5'-GGG CCG GAG GAA GAC TCC TCA TA-3'; REDD1 reverse primer: 5'-CTG TAT GCC AGG CGC AGG AGT TC-3'. Q-PCR with SYBR Green detection was performed on the Applied Biosystems ${ }^{\circledR} 7000$ Real-Time PCR instrument (Life Technologies). Each sample was tested in triplicate. The results were normalized to the expression of the housekeeping Rpl27 gene.

\section{Chromatin immunoprecipitation}

ChIP was performed to assess ER loading on REDD1 EREs using EZ-Magna ChIP A/G ChIP Kit (Millipore, Darmstadt, Germany) per the manufacturer's recommendations. The ER binding sites in human REDD1 promoter were predicted based on HOCOMOCO models of TF binding motifs using ChIP-sequencing and highthroughput systematic evolution of ligands by exponential enrichment (i.e., HT-SELEX) data [31]. HaCaT cells were grown for $36 \mathrm{~h}$ in Phenol red-free DMEM with $10 \%$ charcoal-stripped serum, and then treated with $\mathrm{E}_{2}(1 \mu \mathrm{M})$ for $24 \mathrm{~h}$. Fold enrichment was calculated as $2^{-\Delta \Delta \mathrm{Ct}}$, where $\Delta \mathrm{Ct}=\mathrm{Ct}(\mathrm{IP})-\mathrm{Ct}($ Input $\times \mathrm{DF})$ and $\Delta \Delta \mathrm{Ct}=\Delta \mathrm{Ct}(\mathrm{IP})-$ $\Delta \mathrm{Ct}$ (NS). IP indicates immunoprecipitation, DF indicates the dilution factor, and NS indicates IP with nonspecific IgG. Data are mean $+/-$-standard deviation $(n=3)$. The sequences of 7 putative estrogen response elements in the REDD1 promoter region and primers used for ChIP are detailed in Supplementary Tables 1 and 2.

\section{Statistical analysis}

Means and standard deviations were calculated using Microsoft Excel software (Microsoft, Redmond, WA, USA). The treatment effects in each experiment were compared by 
$t$-test using the GraphPad statistical software (La Jolla, CA, USA) or Microsoft Excel software. For differences between groups, $P<0.05$ was considered significant. Experiments were performed two-three times. In all figures, the results of one representative experiment are shown as mean value $\pm \mathrm{SD}$.

\section{Abbreviations}

AR: androgen receptor; CO: croton oil; DHT: dihydrotestosterone; $\mathrm{E}_{2}$ : 17ß-estradiol; ER: estrogen receptor; ERE: estrogen responsive element; FA: fluocinolone acetonide; GAPDH: glyceraldehyde 3-phosphate dehydrogenase; GCs: glucocorticoids; GR: glucocorticoid receptor; GRE: glucocorticoid-responsive element; KO: knockout; mTOR: mammalian target of rapamycin; mTORC1: mTOR complex 1; REDD1: regulated in development and DNA damage 1; SHR: steroid hormone receptors.

\section{ACKNOWLEDGMENTS AND FUNDING}

Work is supported by R01GM112945, 3R01GM11294502S1, R01AI125366 (to IB and JTD), and NU SDRC 5P30AR057216-08 P\&F project (to IB). We acknowledge Northwestern University SDRC (5 P30 AR057216) morphology and phenotyping Core for technical support.

\section{CONFLICTS OF INTEREST}

The authors state no conflicts of interest.

\section{REFERENCES}

1. Slominski A, Zbytek B, Nikolakis G, Manna PR, Skobowiat C, Zmijewski M, Li W, Janjetovic Z, Postlethwaite A, Zouboulis CC, Tuckey RC. Steroidogenesis in the skin: implications for local immune functions. J Steroid Biochem Mol Biol. 2013; 137:107-123. https://doi.org/10.1016/j. jsbmb.2013.02.006. [PubMed]

2. Slominski AT, Manna PR, Tuckey RC. On the role of skin in the regulation of local and systemic steroidogenic activities. Steroids. 2015; 103:72-88. https://doi.org/10.1016/j. steroids.2015.04.006. [PubMed]

3. Slominski A, Zjawiony J, Wortsman J, Semak I, Stewart J, Pisarchik A, Sweatman T, Marcos J, Dunbar C, C Tuckey R. A novel pathway for sequential transformation of 7-dehydrocholesterol and expression of the P450scc system in mammalian skin. Eur J Biochem. 2004; 271:4178-4188. https://doi.org/10.1111/j.1432-1033.2004.04356.x. [PubMed]

4. Slominski AT, Zmijewski MA, Zbytek B, Tobin DJ, Theoharides TC, Rivier J. Key role of CRF in the skin stress response system. Endocr Rev. 2013; 34:827-884. https:// doi.org/10.1210/er.2012-1092. [PubMed]

5. Slominski AT, Zmijewski MA, Plonka PM, Szaflarski JP, Paus R. How UV Light Touches the Brain and Endocrine System Through Skin, and Why. Endocrinology. 2018; 159:19922007. https://doi.org/10.1210/en.2017-03230. [PubMed]
6. Hengge UR, Ruzicka T, Schwartz RA, Cork MJ. Adverse effects of topical glucocorticosteroids. J Am Acad Dermatol. 2006; 54:1-15. https://doi.org/10.1016/j.jaad.2005.01.010. [PubMed]

7. Schoepe S, Schäcke H, May E, Asadullah K. Glucocorticoid therapy-induced skin atrophy. Exp Dermatol. 2006; 15:406420. https://doi.org/10.1111/j.0906-6705.2006.00435.x. [PubMed]

8. Barnes L, Kaya G, Rollason V. Topical corticosteroid-induced skin atrophy: a comprehensive review. Drug Saf. 2015; 38:493-509. https://doi.org/10.1007/s40264-015-0287-7. [PubMed]

9. Woodbury R, Kligman AM. The hairless mouse model for assaying the atrophogenicity of topical corticosteroids. Acta Derm Venereol. 1992; 72:403-406. [PubMed]

10. Zheng PS, Lavker RM, Lehmann P, Kligman AM. Morphologic investigations on the rebound phenomenon after corticosteroid-induced atrophy in human skin. J Invest Dermatol. 1984; 82:345-352. https://doi.org/10.1111/15231747.ep12260665. [PubMed]

11. Britto FA, Begue G, Rossano B, Docquier A, Vernus B, Sar C, Ferry A, Bonnieu A, Ollendorff V, Favier FB. REDD1 deletion prevents dexamethasone-induced skeletal muscle atrophy. Am J Physiol Endocrinol Metab. 2014; 307:E983-E993. https:// doi.org/10.1152/ajpendo.00234.2014. [PubMed]

12. Baida G, Bhalla P, Kirsanov K, Lesovaya E, Yakubovskaya M, Yuen K, Guo S, Lavker RM, Readhead B, Dudley JT, Budunova I. REDD1 functions at the crossroads between the therapeutic and adverse effects of topical glucocorticoids. EMBO Mol Med. 2015; 7:42-58. https:// doi.org/10.15252/emmm.201404601. [PubMed]

13. Azzi L, El-Alfy M, Martel C, Labrie F. Gender differences in mouse skin morphology and specific effects of sex steroids and dehydroepiandrosterone. J Invest Dermatol. 2005; 124:22-27. https://doi.org/10.1111/j.0022-202X.2004.23545.x. [PubMed]

14. Dao H Jr, Kazin RA. Gender differences in skin: A review of the literature. Gend Med. 2007; 4:308-328. https://doi. org/10.1016/S1550-8579(07)80061-1. [PubMed]

15. Kong BY, Haugh IM, Schlosser BJ, Getsios S, Paller AS. Mind the gap: Sex bias in basic skin research. J Invest Dermatol. 2016; 136:12-14. https://doi.org/10.1038/ JID.2015.298. [PubMed]

16. Duma D, Collins JB, Chou JW, Cidlowski JA. Sexually dimorphic actions of glucocorticoids provide a link to inflammatory diseases with gender differences in prevalence. Sci Signal. 2010; 3:ra74. https://doi.org/10.1126/ scisignal.2001077. [PubMed]

17. Chrousos GP. Stress and sex versus immunity and inflammation. Sci Signal. 2010; 3:pe36. https://doi. org/10.1126/scisignal.3143pe36. [PubMed]

18. Hall G, Phillips TJ. Estrogen and skin: the effects of estrogen, menopause, and hormone replacement therapy on the skin. J Am Acad Dermatol. 2005; 53:555-568. https:// doi.org/10.1016/j.jaad.2004.08.039. [PubMed] 
19. Rzepecki AK, Murase JE, Juran R, Fabi SG, McLellan BN. Estrogen-deficient skin: The role of topical therapy. Int J Womens Dermatol. 2019; 5:85-90. https://doi. org/10.1016/j.ijwd.2019.01.001. [PubMed]

20. Quinn M, Ramamoorthy S, Cidlowski JA. Sexually dimorphic actions of glucocorticoids: beyond chromosomes and sex hormones. Ann N Y Acad Sci. 2014; 1317:1-6. https://doi.org/10.1111/nyas.12425. [PubMed]

21. Wang H, Kubica N, Ellisen LW, Jefferson LS, Kimball SR. Dexamethasone represses signaling through the mammalian target of rapamycin in muscle cells by enhancing expression of REDD1. J Biol Chem. 2006; 281:39128-39134. https:// doi.org/10.1074/jbc.M610023200. [PubMed]

22. Kumari R, Willing L, Jefferson LS, Simpson IA, Kimball SR. REDD1 (regulated in development and DNA damage response 1) expression in skeletal muscle as a surrogate biomarker of the efficiency of glucocorticoid receptor blockade. Biochem Biophys Res Commun. 2011; 412:644647. https://doi.org/10.1016/j.bbrc.2011.08.017. [PubMed]

23. Lesovaya E, Agarwal S, Readhead B, Vinokour E, Baida G, Bhalla P, Kirsanov K, Yakubovskaya M, Platanias LC, Dudley JT, Budunova I. Rapamycin Modulates Glucocorticoid Receptor Function, Blocks Atrophogene REDD1, and Protects Skin from Steroid Atrophy. J Invest Dermatol. 2018; 138:1935-1944. https://doi.org/10.1016/j. jid.2018.02.045. [PubMed]

24. Park KK, Ko DH, You Z, Heiman AS, Lee HJ. Synthesis and pharmacological evaluations of new steroidal antiinflammatory antedrugs: $9 \alpha$-Fluoro- $11 \beta, 17 \alpha, 21$-trihydroxy3,20-dioxopregna-1,4-diene-16 $\alpha$-carboxylate (FP16CM) and its derivatives. Steroids. 2006; 71:83-89. https://doi. org/10.1016/j.steroids.2005.08.005. [PubMed]

25. Chebotaev D, Yemelyanov A, Zhu L, Lavker RM, Budunova I. The tumor suppressor effect of the glucocorticoid receptor in skin is mediated via its effect on follicular epithelial stem cells. Oncogene. 2007; 26:3060-3068. https://doi. org/10.1038/sj.onc.1210108. [PubMed]

26. Schoepe S, Schäcke H, Bernd A, Zöller N, Asadullah $\mathrm{K}$. Identification of novel in vitro test systems for the determination of glucocorticoid receptor ligand-induced skin atrophy. Skin Pharmacol Physiol. 2010; 23:139-151. https://doi.org/10.1159/000270386. [PubMed]

27. Baida G, Bhalla P, Yemelyanov A, Stechschulte LA, Shou W, Readhead B, Dudley JT, Sánchez ER, Budunova I. Deletion of the glucocorticoid receptor chaperone FKBP51 prevents glucocorticoid-induced skin atrophy. Oncotarget. 2018; 9:34772-34783. https://doi.org/10.18632/oncotarget.26194. [PubMed]

28. Peržel’ová V, Sabol F, Vasilenko T, Novotný M, Kováč I, Slezák M, Durkáč J, Hollý M, Pilátová M, Szabo P, Varinská L, Čriepoková Z, Kučera T, et al. Pharmacological activation of estrogen receptors- $\alpha$ and $-\beta$ differentially modulates keratinocyte differentiation with functional impact on wound healing. Int J Mol Med. 2016; 37:21-28. https://doi.org/10.3892/ijmm.2015.2351. [PubMed]
29. Seiffert K, Seltmann H, Fritsch M, Zouboulis CC. Inhibition of 5alpha-reductase activity in SZ95 sebocytes and HaCaT keratinocytes in vitro. Horm Metab Res. 2007; 39:141-148. https://doi.org/10.1055/s-2007-961814. [PubMed]

30. Agarwal S, Mirzoeva S, Readhead B, Dudley JT, Budunova I. PI3K inhibitors protect against glucocorticoid-induced skin atrophy. EBioMedicine. 2019; 41:526-537. https://doi. org/10.1016/j.ebiom.2019.01.055. [PubMed]

31. Yevshin I, Sharipov R, Valeev T, Kel A, Kolpakov F. GTRD: a database of transcription factor binding sites identified by ChIP-seq experiments. Nucleic Acids Res. 2017; 45:D61D67. https://doi.org/10.1093/nar/gkw951. [PubMed]

32. Lili LN, Klopot A, Readhead B, Baida G, Dudley JT, Budunova I. Transcriptomic Network Interactions in Human Skin Treated with Topical Glucocorticoid Clobetasol Propionate. J Invest Dermatol. 2019; 139:2281-2291. https://doi.org/10.1016/j.jid.2019.04.021. [PubMed]

33. Stevenson S, Thornton J. Effect of estrogens on skin aging and the potential role of SERMs. Clin Interv Aging. 2007; 2:283-297. https://doi.org/10.2147/CIA.S798. [PubMed]

34. Truong TH, Lange CA. Deciphering Steroid Receptor Crosstalk in Hormone-Driven Cancers. Endocrinology. 2018; 159:38973907. https://doi.org/10.1210/en.2018-00831. [PubMed]

35. Beato M, Herrlich P, Schütz G. Steroid hormone receptors: many actors in search of a plot. Cell. 1995; 83:851-7. https:// doi.org/10.1016/0092-8674(95)90201-5. [PubMed]

36. Vahrenkamp JM, Yang $\mathrm{CH}$, Rodriguez AC, Almomen A, Berrett KC, Trujillo AN, Guillen KP, Welm BE, Jarboe EA, Janat-Amsbury MM, Gertz J. Clinical and genomic crosstalk between glucocorticoid receptor and estrogen receptor $\alpha$ in endometrial cancer. Cell Rep. 2018; 22:2995-3005. https:// doi.org/10.1016/j.celrep.2018.02.076. [PubMed]

37. Karmakar S, Jin Y, Nagaich AK. Interaction of glucocorticoid receptor (GR) with estrogen receptor (ER) alpha and activator protein 1 (AP1) in dexamethasone-mediated interference of ERalpha activity. J Biol Chem. 2013; 288:24020-24034. https://doi.org/10.1074/jbc.M113.473819. [ [PubMed]

38. West DC, Pan D, Tonsing-Carter EY, Hernandez KM, Pierce CF, Styke SC, Bowie KR, Garcia TI, Kocherginsky M, Conzen SD. GR and ER Coactivation Alters the Expression of Differentiation Genes and Associates with Improved ER+ Breast Cancer Outcome. Mol Cancer Res. 2016; 14:707719. https://doi.org/10.1158/1541-7786.MCR-15-0433. [PubMed]

39. Whirledge S, Xu X, Cidlowski JA. Global gene expression analysis in human uterine epithelial cells defines new targets of glucocorticoid and estradiol antagonism. Biol Reprod. 2013; 89:66. https://doi.org/10.1095/biolreprod.113.111054. [PubMed]

40. Rhen T, Grissom S, Afshari C, Cidlowski JA. Dexamethasone blocks the rapid biological effects of 17beta-estradiol in the rat uterus without antagonizing its global genomic actions. FASEB J. 2003; 17:1849-1870. https://doi.org/10.1096/fj.02-1099com. [PubMed] 